\title{
Varicella-Zoster Virus Keratitis with Asymptomatic Conjunctival Viral Shedding in the Contralateral Eye
}

\author{
Akio Miyakoshi $^{a} \quad$ Masaya Takemoto $^{\mathrm{b}}$ Kimiyasu Shiraki $^{\mathrm{b}}$ \\ Atsushi Hayashi ${ }^{a}$ \\ Departments of ${ }^{a}$ Ophthalmology and ${ }^{b}$ Virology, Graduate School of Medicine \\ and Pharmaceutical Sciences, University of Toyama, Toyama, Japan
}

\section{Key Words}

Varicella-zoster virus $\cdot$ Keratitis $\cdot$ Asymptomatic shedding $\cdot$ Tear fluid $\cdot$ PCR

\begin{abstract}
Purpose: To report a case of varicella-zoster virus (VZV) keratitis with detection of VZV DNA in the tear fluid of not only the symptomatic eye but also the contralateral asymptomatic eye by polymerase chain reaction (PCR).

Methods: This is a case report. A 63-year-old otherwise healthy woman presented with circular corneal ulcer and stromal opacity with infiltration accompanied by mild conjunctival and ciliary injections in the left eye. Bacterial cultures of the corneal scrapings and virus PCR analyses of tear fluid from both eyes were performed.
\end{abstract}

Results: No pathogen was found by bacterial cultures. PCR was negative for Acanthamoeba, herpes simplex virus and cytomegalovirus, but positive for VZV. VZV DNA was also detected in the unaffected eye. Based on the diagnosis of VZV keratitis, oral valacyclovir and acyclovir eye ointment were administered to the corneal infected eye. The infected eye was healed and VZV DNA turned negative in the tear fluid of the treated eye after 6 months of treatment; however, VZV DNA was still positive in the tear fluid of the contralateral eye. Conclusions: To our knowledge, this is the first case report of the detection of VZV DNA in the tear fluid of both affected and unaffected eyes in a patient with VZV keratitis. Asymptomatic conjunctival shedding of VZV may continue in the healthy unaffected eye in VZV keratitis patients. 


\section{Introduction}

Herpes zoster ophthalmicus (HZO), a serious sight-threatening condition, has been linked to varicella-zoster virus (VZV) reactivation within the trigeminal ganglion $[1,2]$. Incidence rates of $\mathrm{HZO}$ complicating herpes zoster in various population surveys have ranged from 8 to $56 \%[3,4]$. The frontal branch within the first division of the trigeminal nerve is most frequently involved, and $50-72 \%$ of patients experience direct ocular involvement [2].

Early diagnosis is critical to prevent progressive corneal involvement and potential loss of vision [4]. The standard approach to HZO is to initiate antiviral therapy (acyclovir, valacyclovir, or famciclovir), to limit VZV replication, and to use adjunctive topical steroid drops to reduce the inflammatory responses of keratitis and iritis $[1,2$, $4,5]$. Polymerase chain reaction (PCR) examinations are valuable for diagnosis of VZV keratitis because the clinical appearances of corneal keratitis caused by viruses, bacteria, and fungus are difficult to differentiate.

Asymptomatic viral shedding of VZV from the saliva has been shown [6, 7]; however, asymptomatic viral shedding in tear fluid has not yet been described. In this report, we document a patient, with VZV keratitis diagnosed by detection of VZV DNA with PCR in the affected eye, who showed asymptomatic viral shedding of VZV in the tear fluid of the healthy unaffected eye.

\section{Case Report}

Clinical Course of the Patient

A 63-year-old otherwise healthy woman with a history of soft contact lens use was referred to our hospital after 2 days of failed intensive topical empirical therapy for presumed bacterial keratitis in the left eye on July 1, 2011 (fig. 1a). She had no history of injury by a foreign body or previous ocular surgery. The patient reported severe pain, tearing and a foreign-body sensation in the left eye. Her visual acuity was 0.8 with correction in the right eye and 0.3 with correction in the left eye. No increase in intraocular pressure was observed in either eye. On slit-lamp examination, the left eye showed conjunctival and ciliary injection, and a corneal ulcer with underlying dense anterior corneal stromal infiltration. Slight to mild inflammation was observed in the anterior chamber of the left eye. The right eye showed only mild cataract with no inflammation (fig. 1b). Corneal scraping was carried out for bacterial and fungal culturing. The patient was admitted to the hospital and advised to continue the same medications, gatifloxacin $0.3 \%$ eye drops, cefmenoxime $0.5 \%$ eye drops, and ofloxacin $0.3 \%$ eye ointment, but the corneal findings were not improved and were consistent with the lack of positive culture for bacteria or fungus. On July 7, corneal scrapings were tested for Acanthamoeba using PCR, and chlorhexidine gluconate $0.02 \%$ eye drops, oral itraconazole $(200$-mg tablets), and fluconazole $0.2 \%$ eye drops were started. Negative PCR and cultures for Acanthamoeba at 24, 48, and $72 \mathrm{~h}$ of incubation were reported. On July 9, PCR testing for Acanthamoeba was repeated using new corneal scrapings, but the result was negative. On July 11, tear fluid was tested by PCR for herpes simplex virus (HSV), VZV, and cytomegalovirus (CMV). Positive PCR results for VZV were obtained and the patient was diagnosed with VZV keratitis. Previous therapy was stopped and oral valacyclovir (1,000-mg tablets 3 times a day for 1 week), and acyclovir eye ointment were started [8]. On July 14 , after the epithelial defect was improved, fluorometholone $0.1 \%$ eye drops were added (fig. 1c). Resolution of the corneal infiltrate and a clear chamber were achieved. After that, acyclovir eye ointment and fluorometholone $0.1 \%$ eye drops were tapered. At the most recent follow-up visit ( 6 months after the initial presentation), residual corneal stromal opacity was observed, but no vascularization or recurrence of infiltration was detected (fig. 1d). 
DNA Analyses of the Corneal Specimen and Tear Fluid

DNA was extracted from clinical specimens using QIAamp DNA Mini Kit (QIAGEN) per the manufacturer's instructions. Briefly, corneal scrapings or tear fluid collected with a filter paper strip were suspended in $200 \mu \mathrm{l}$ of phosphate buffered saline containing $100 \mu \mathrm{g}$ proteinase $\mathrm{K}$ per $\mu \mathrm{l}$, mixed with an equal volume of buffer $\mathrm{AL}$, and then incubated at $56^{\circ} \mathrm{C}$ for $10 \mathrm{~min}$. After removal of debris or filter paper strip by spin down, DNA was purified from the supernatant with a QIAamp Mini Spin Column and eluted in $50 \mu \mathrm{l}$ of TE buffer (10 mM Tris-HCl, pH 8.0, and 1 mM EDTA, pH 8.0).

To amplify and detect DNA fragments of several pathogens, we modified the PCR protocol reported by Tanaka et al. [9]. The following primer pairs were used in this study: Acant-F (5'CCCAGATCGTTTACCGTGAA-3') and Acant-R (5'-TAAATATTAATGCCCCCAACTATCC-3'), HSV-F (5'GCCAAGAAAAAGTACATCGGCGTCATC-3') and HSV-R (5'-TGAGGACAAAGTCCTGGATGTCCCTCT-3'), VZV-F (5'-TCCGACATGCAGTCAATTTCAACGTC-3') and VZV-R (5'-GGTCGGGTAGACGCTACCACTCGTTT3'), CMV-F (5'-GCGCGTACCGTTGAAAGAAAAGCATAA-3') and CMV-R (5'-TGGGCACTCGGGTCTTCATCTCTTTAC-3').

Lengths of PCR products were about $180 \mathrm{bp}$ for Acanthamoeba, $292 \mathrm{bp}$ for HSV-1/2, $161 \mathrm{bp}$ for VZV, and $131 \mathrm{bp}$ for CMV. Fifty microliters of reaction mixture composed of $5 \mu \mathrm{l}$ of DNA sample, $1 \times$ PCR buffer for KOD FX Neo (Toyobo, Japan), $0.4 \mathrm{mM}$ dNTPs, $0.2 \mu \mathrm{M}$ of each primer set, and 1 unit of KOD FX Neo (Toyobo) was subjected to PCR reaction as follows. After an initial denaturation at $94^{\circ} \mathrm{C}$ for $3 \mathrm{~min}$, the reaction mixture was subjected to touchdown protocol comprising 10 cycles of denaturation of $98^{\circ} \mathrm{C}$ for $10 \mathrm{~s}$, annealing at $70-61^{\circ} \mathrm{C}$ for $15 \mathrm{~s}$ with $1^{\circ} \mathrm{C}$ decrease in temperature per cycle, and elongation at $68^{\circ} \mathrm{C}$ for $30 \mathrm{~s}$ and was followed by 30 cycles of $98^{\circ} \mathrm{C}$ for $10 \mathrm{~s}, 60^{\circ} \mathrm{C}$ for $15 \mathrm{~s}$, and $68^{\circ} \mathrm{C}$ for $30 \mathrm{~s}$. The PCR products were analyzed by $3 \%$ agarose gel electrophoresis.

No specific band was detected using primers against Acanthamoeba as shown in fig. 2a. Three herpes viruses related to ocular diseases, HSV, VZV, and CMV, were examined, and only VZV DNA was amplified among them (fig. 2b). Tear fluid collected from both the affected and the healthy unaffected eyes was also analyzed for VZV before and after administration of acyclovir ointment. Fig. 2c shows that VZV was positive not only in the tear fluid of the affected eye but also in that of the healthy eye before treatment with acyclovir ointment. After acyclovir administration, VZV DNA was still detected in the healthy eye though it had disappeared from the affected eye.

\section{Discussion}

HSV is known to be latent in the trigeminal ganglia and the cornea. Asymptomatic shedding of HSV-1 has been observed in tears of healthy people $[10,11]$. Although HSV1 DNA has been found in the corneas of patients with no clinical or diagnosed history of herpetic keratitis [12], the amount of HSV-1 DNA is much less than in the corneas of patients with a diagnosis of herpetic keratitis.

VZV is also latent in the trigeminal ganglia $[13,14]$, and recently subclinical asymptomatic VZV shedding has been reported in the saliva of astronauts in stressed environments $[6,7]$. However, asymptomatic VZV shedding in corneal disease has not yet been reported. Here, we report asymptomatic VZV shedding in the healthy unaffected eye of a VZV keratitis patient. Detection of VZV in bilateral eyes has been reported in patients with Bell's palsy [15] and Ramsay Hunt syndrome [16], but this is the first report of detection in a case of corneal stromal keratitis. This may suggest that simultaneous reactivation in both trigeminal ganglia by unknown stress caused shedding of VZV in the tear fluid resulting in keratitis in 1 eye. VZV was not detected in the tear fluid after topical and oral acyclovir in the affected eye, while VZV was detected in the contralateral eye without topical treatment. VZV in the tear fluid was not influenced by oral acyclovir but by topical acyclovir. This may indicate a rare possibility that a low amount of VZV genome might be derived not from the trigeminal ganglia but 
from the cornea, as the HSV genome was detected in the tear fluid and the cornea [1012]. The difference in the occurrence of keratitis might be due to the amount of virus as suggested by Kaufman et al. [10]. In this case, only corneal scraping showed detectable levels of VZV DNA (5.6 $\times 10^{2}$ copies per sample), while viral DNA in the tear fluid was below the detection limit of 20 copies per reaction by SYBR-Green method (data not shown).

As shown in a study of Ramsay Hunt syndrome, detection rates of VZV DNA in the tear fluid increased between the 2 nd and 4 th weeks compared to the first 2 weeks on both the affected and unaffected sides [16]. Our case happened to be examined during the time period 2-4 weeks after onset because of a prolonged diagnostic process due to the confusing clinical appearances of the keratitis. This might be a reason why VZV DNA could be detected in the tear fluid of the healthy unaffected eye.

In this report, we showed asymptomatic shedding of VZV in the tear fluid of the healthy unaffected eye in a VZV keratitis patient. Further studies are needed to examine rates and duration of detection of VZV DNA in such patients.

\section{Disclosure Statement}

The authors have no financial interest relevant to this paper.
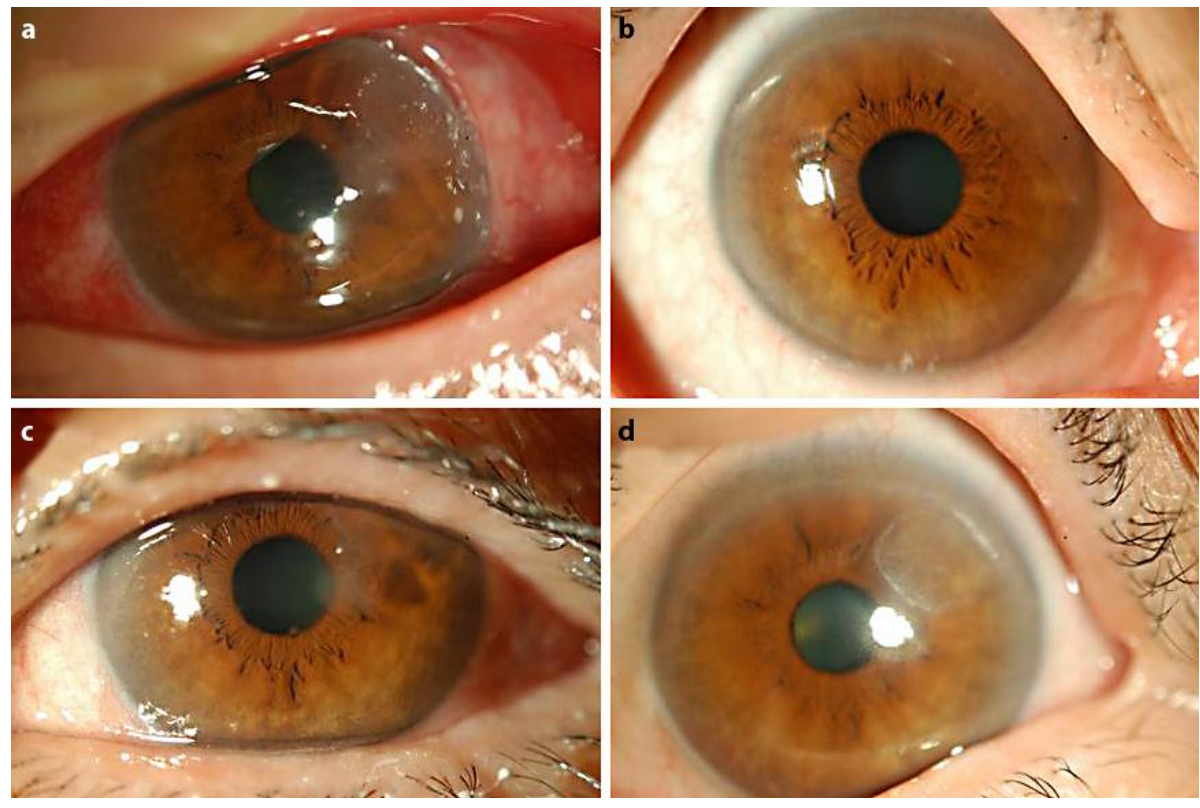

Fig. 1. Slit-lamp photographs of both eyes before and after treatment. a Corneal epithelial defect and keratitis in the left eye. b Healthy contralateral right eye. $\mathbf{c} 9$ days after initiation of treatment of the left eye. $\mathbf{d} 25$ days after initiation of treatment of the left eye. 
a

b

Acanth-

M amoeba

M HSV VZV CMV
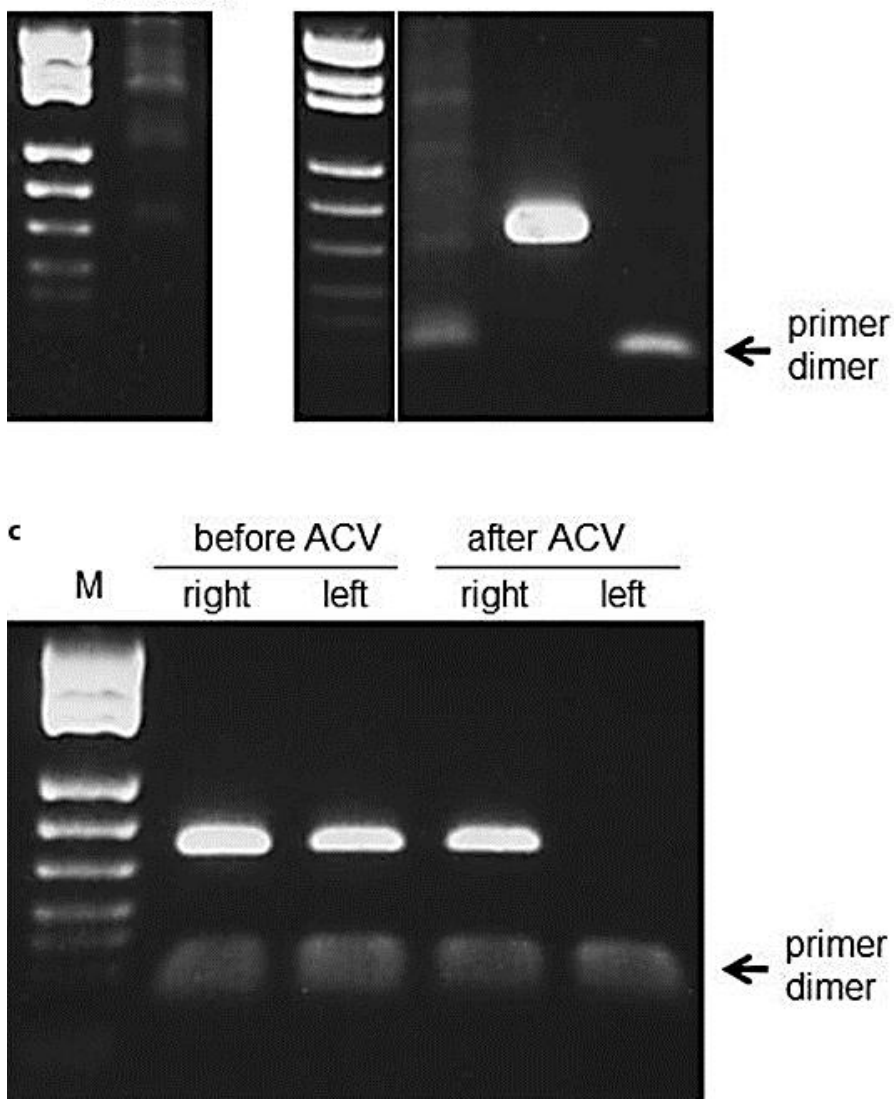

Fig. 2. Agarose gel electrophoresis of the PCR products from corneal scratches for Acanthamoeba (a), HSV, VZV, and CMV (b). Agarose gel electrophoresis of PCR products of VZV in the tear fluid (c). VZV DNA was detected in both eyes before acyclovir treatment and it was not detected in the left eye with VZV keratitis after acyclovir treatment; however, it was still detected in the untreated healthy right eye.

\section{References}

1 Liesegang TJ: Diagnosis and therapy of herpes zoster ophthalmicus. Ophthalmology 1991;98:12161229.

-2 Pavan-Langston D: Herpes zoster ophthalmicus. Neurology 1995;45:S50-S51.

-3 Ragozzino MW, Melton L Jr, Kurland LT, et al: Population-based study of herpes zoster and its sequelae. Medicine (Baltimore) 1982;61:310-316.

-4 Severson EA, Baratz KH, Hodge DO, et al: Herpes zoster ophthalmicus in Olmsted County, Minnesota: have systemic antivirals made a difference? Arch Ophthalmol 2003;121:386-390.

5 Herbort CP, Buechi ER, Piguet B, et al: High-dose oral acyclovir in acute herpes zoster ophthalmicus: the end of the corticosteroid era. Curr Eye Res 1991;10(suppl):171-175.

6 Mehta SK, Cohrs RJ, Forghani B, et al: Stress-induced subclinical reactivation of varicella zoster virus in astronauts. J Med Virol 2004;72:174-179.

7 Cohrs RJ, Mehta SK, Schmid DS, et al: Asymptomatic reactivation and shed of infectious varicella zoster virus in astronauts. J Med Virol 2008;80:1116-1122. 
8 Sanjay S, Huang P, Lavanya R: Herpes Zoster Ophthalmicus. Curr Treat Opinions Neurol 2011;13:79-91.

-9 Tanaka T, Kogawa K, Sasa H, et al: Rapid and simultaneous detection of 6 types of human herpes virus (herpes simplex virus, varicella-zoster virus, Epstein-Barr virus, cytomegalovirus, human herpes virus 6A/B, and human herpes virus 7) by multiplex PCR assay. Biomed Res 2009;30:279-285.

10 Kaufman HE, Azcuy AM, Varnell ED, et al: HSV-1 DNA in tears and saliva of normal adults. Invest Ophthalmol Vis Sci 2005;46:241-247.

11 Shimomura Y, Higaki S: The kinetics of herpes virus on the ocular surface and suppression of its reactivation. Cornea 2011;30(suppl 1):S3-S7.

12 van Gelderen BE, Van der Lelij A, Treffers WF, et al: Detection of herpes simplex virus type 1, 2 and varicella zoster virus DNA in recipient corneal buttons. Br J Ophthalmol 2000;84:1238-1243.

13 Kennedy PG, Grinfeld E, Gow JW: Latent varicella-zoster virus is located predominantly in neurons in human trigeminal ganglia. Proc Natl Acad Sci USA 1998;95:4658-4662.

14 Cohrs RJ, Randall J, Smith J, et al: Analysis of individual human trigeminal ganglia for latent herpes simplex virus type 1 and varicella-zoster virus nucleic acids using real-time PCR. J Virol 2000;74:1146411471.

15 Pitkaranta A, Piiparinen H, Mannonen L, et al: Detection of human herpes virus 6 and varicella-zoster virus in tear fluid of patients with Bell's palsy by PCR. J Clin Microbiol 2000;38:2753-2755.

16 Hiroshige K, Ikeda M, Hondo R: Detection of varicella zoster virus DNA in tear fluid and saliva of patients with Ramsay Hunt syndrome. Otol Neurotol 2002;23:602-607. 